\title{
Modelling and Optimisation in the Design of Pipeline Network Systems Using Ant Colony Optimisation Algorithm (ACO)
}

Amin Nakhaei ${ }^{{ }^{*}}$ and Faeze Soltani ${ }^{2}$

${ }^{1}$ MSc. Petroleum \& Gas Eng., University of Salford, Manchester, UK.

${ }^{2}$ BSc. Chemical Eng., University of Kerman, Kerman, Iran.

\section{*Corresponding Author: \\ ×aminnakhei@hotmail.com}

Received: 15 September, 2021

Accepted: 30 October, 2021

Published: 25 December, 2021

\begin{abstract}
This paper covers the Ant Colony Optimisation Algorithm (ACO) as an optimisation method and discusses and recommends the utilization of the model in design and analysing of varies parameters related in the oil and gas pipeline network systems. This is to achieve the optimum length of the pipeline, pressure and flow rate. Ant Colony Optimisation Algorithm (ACO) is capable of finding minimum path between several paths with their limitations and decreases pipe lengths from the sources to their destinations. It can be used in petroleum and gas refineries, transmissions and distributions lines. The theoretical and mathematical example of Ant Colony Optimisation Algorithm (ACO) between two places were carried and calculated. Optimum length is calculated about $100 \mathrm{~cm}$ with optimum pressure about $2440 \mathrm{psi}$ and flow rate about $83 * 10^{6} \mathrm{~mm}^{3} / \mathrm{h}$. An example was designed based on the random variables results from 10 to $96 \mathrm{~km}$ for MATLAB Software and 0.1 to $1 \mathrm{~km}$ for ANTCOL Software as Stochastic Variables (SV) of length $(\mathrm{Km})$ between 14 stages which may show as 'SV-Matrix = Randi ([10 96], 14)' and Randi ([0.1 1.5], 14)". For each iterations the SV matrixes are showed varies range of integrity. An example was assumed between 14 places with varies range of limitations which will be occurred during a pipeline project (FIG. 6 as an initially supposition graph) to find minimum path between stages to conclude optimum range of pressure and flow rate of oil and gases based on the optimum minimum paths of pipeline network systems. SV matrixes are used based on the MATLAB Code and ANTCOL software by the CPU core 2 Duo "Intel" based on the ACO algorithm formulas. The output lines, graphs and diagrams of ACO algorithm are showed the minimum optimum path between 14 stages about 526 $\mathrm{km}$ with start point from station 6 and optimum flow-rate $0.09810^{6} \mathrm{~mm}^{3} / \mathrm{hrr}$ and pressure drop about 714.638 bar while $3.631 \mathrm{~km}$ as minimum length with optimum flow rate $1.515480 * 10^{6} \mathrm{~mm}^{3} / \mathrm{hrr}$ and pressure drop about 1192.83 bar are found by ANTCAL results. The results proved the ability of ACO algorithm to find the optimum path with its effects on the other importance parameters, especially in the pipeline network systems, distribution and transmission lines and refineries.
\end{abstract}

Keywords: ACO, Ant Colony Optimisation Algorithm, MATLAB, ANTCOL

\section{Introduction}

In recent decades, increasing the demand of oil and gas caused increasing in the amount and length of pipeline network systems. Consideration to the design of any distribution and transmission systems are the main objects for governments and companies to find and use suitable methods to reduce the cost and delivery times and optimisation to get maximum performance in the pipeline networks. This paper discusses and 
recommends an Ant Colony Optimisation Algorithm (ACO) as a powerful optimisation method to reduce and define particular length of pipelines.

Different types of methods and software(s) are now used in many companies to calculate the value of flow rate $(\mathrm{Q})$, pressure drop $(\Delta \mathrm{p})$, diameter $(\mathrm{d})$ and length (L) where are governing parameters in the oil and gas industry. Length, diameter, thickness and type of pipes are the most effective variables on estimating the final cost and performance of pipeline networks. Pipeline length is the critical value for transmission and distribution pipeline network systems which covers about $60 \%$ of the overall cost of pipeline network, it is thus important to consider and estimate the pipeline length to choose minimum length with maximum performance utilising an Ant Colony Optimisation Algorithm (ACO).

As far as the authors are concerned the corresponding algorithm has had no application in such a manner that is proposed here. That is to provide minimum length of pipes through a number of paths to the final destination where traditionally it may needs to have several more length added to the give network systems. The algorithm is sufficiently flexible and can also be used in different stage of compressors, refineries pipelines, LNG process and other products to find minimum path from a special product to another one.

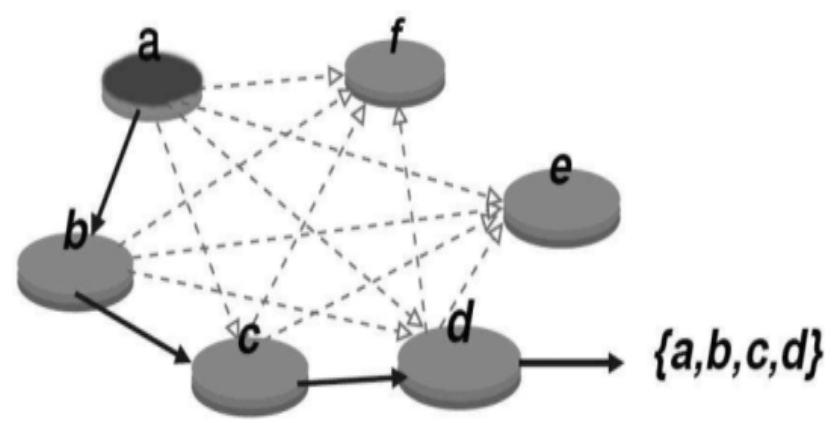

Figure 1. Minimum path between points a to $\mathrm{d}$

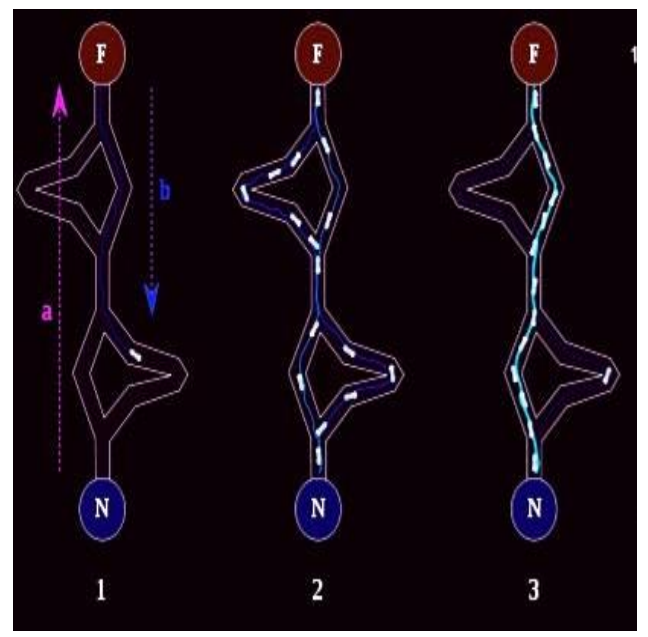

Figure 2. Ants behaviour in ACO algorithm

Pressure drop, flow rate and velocity are the critical parameters to deliver the gas or oil to the customers and to the final destinations. Outlet pressure is always less than inlet pressure due to friction loss and other related factors which are also problematic for pipeline networks. Furthermore, to maintain, say, the gas velocity under $20 \mathrm{~m} / \mathrm{s}$ with the corresponding flow rate in estimating the capacity of pipeline networks in peak load or winter load or to extend the distribution pipeline, necessitates to optimise pressure drop and require flow rate by optimum length. This paper discusses an Ant Colony Optimisation Algorithm
(ACO) and its applications in transmission and distribution pipeline networks and oil and gas industry to consider minimum path between the products to reduce the pipe length and to decrease the overall capital and operating costs of the pipeline network systems.

\section{What is ACO?}

The Ant Colony Optimisation Algorithm (ACO) is a probabilistic technique for solving computational problems which can be reduced to finding minimum 
paths through various graphical representations. Initially proposed by Marco Dorigo in 1992 in his PhD thesis, the first algorithm was aiming to search for an optimal path in a graph, based on the behaviour of ants seeking a path between their colony and a source of food. In the natural world an initiate ants moving aimlessly randomly and upon finding food return to their colony while laying down pheromone, where they make it in their bodies. They are likely not to keep travelling at random, if other ants find such a path (other path), but to instead follow the trail returning and reinforcing if they eventually find food(s). By less travelling in the long paths, the pheromones trail starts to evaporate, thus reducing the path attractive for other ants. A short path gets trek over move frequently and thus the pheromone density become higher on shorter path than longer ones. More travelling on the short path shows the optimum path with minimum distance to foods and eventually leads all the ants following a single path. The picture below shows in the figure 2 the behaviour of ants to choose minimum distance.

1. The first ant finds the food source $(\mathrm{F})$, the returns to the nest $(\mathrm{N})$ and leaving behind a trail pheromone (b)

2. Other ants randomly follow four possible ways, but fortify of the runway makes it more attractive as the shortest route with more evaporation of pheromones in long paths.

3. Ants take the shortest route and long portions of other way lose their trail pheromones.

The advantages of this algorithm than other algorithms are, as follow:

1. Find minimum path between two or several stations

2. Self-organizing, if any changes happened in the amount of paths or states the ACO algorithm can check new paths or states without re-start from first stage

3. Powerful in finding the optimum path

4. Flexibility,

5. Same performance for optimum path, not any effect from new additional path

Formulations

At each repetition of the algorithm, each ant moves from state $\mathrm{x}$ to state $\mathrm{y}$, corresponding to a more complete intermediate solution, thus each ant $\mathrm{K}$ computes a set $\mathrm{A}^{\mathrm{k}}$ xy of possible developments to its current state in each iteration for ant $K$.

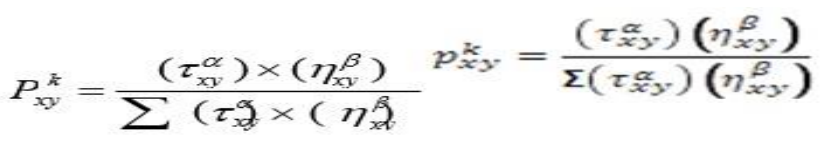

Where:

- $\mathrm{p}^{\mathrm{k} y}$ is probability of moving from state $\mathrm{x}$ to state $\mathrm{y}$

- $\tau_{x y}^{\alpha}$ is the amount of pheromone deposited for transition from state $\mathrm{x}$ to state $\mathrm{y}$ and $(\alpha \geq 0)$

where $\square$ is a parameter to control the influence of $\tau_{x y}$

$\eta_{x y}^{\beta}$ is desirability of state transition xy and $(\beta \geq 1)$

where $\boldsymbol{\beta}$ is a parameter to control the influence of

$\eta_{x y}$, also

$\eta_{x y}^{\beta}=1 / d_{x y}$

Where $d$ is distance between $x y$

Pheromone update achieved after complete the solution by ants, the trails are updated by

$\tau_{x y}^{k}=\left(1-\mathrm{I}\right.$ ?) $\tau_{x y}^{k}+\Delta \tau_{x y}^{k}$ (3)

Where $L_{k}$ is the cost of Kth ant's tour, Q is amount of pheromone deposited for each ant and is about 10

$$
\begin{gathered}
\tau_{x y}^{k}=(1-\mathrm{I} ?) \\
\tau_{x y_{1} 1}^{k}(t)=\tau_{x y 0}^{k}(t)+\Delta \tau_{x y}^{k}+\left(\Delta \tau_{x y}^{A_{0}^{*} A_{1}}(t) \underset{1}{x} \rho\right)
\end{gathered}
$$

Where:

- $\tau_{x y}^{k}$ is amount of pheromone deposited for a state transition $\mathrm{xy}$

- I? is pheromone evaporation coefficient

$\Delta \tau_{x y}^{k}$ is the amount of pheromone deposited (5)

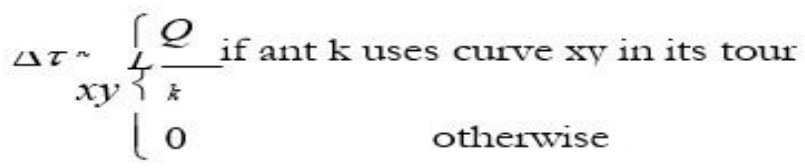

$\Delta \pi_{x y}^{k}\left\{\begin{array}{lr}\frac{Q}{L_{k}} & \text { if ant } k \text { uses cure } x y \text { in its towr } \\ 0 & \text { other wise }\end{array}\right.$

This diagram shows the ACO algorithm that used in some different software like MATLAB, EXCEL, $\mathrm{C}++, \ldots$ and some particular software for ACO algorithm are MYRMEDROME, ANTSIM, ... . 


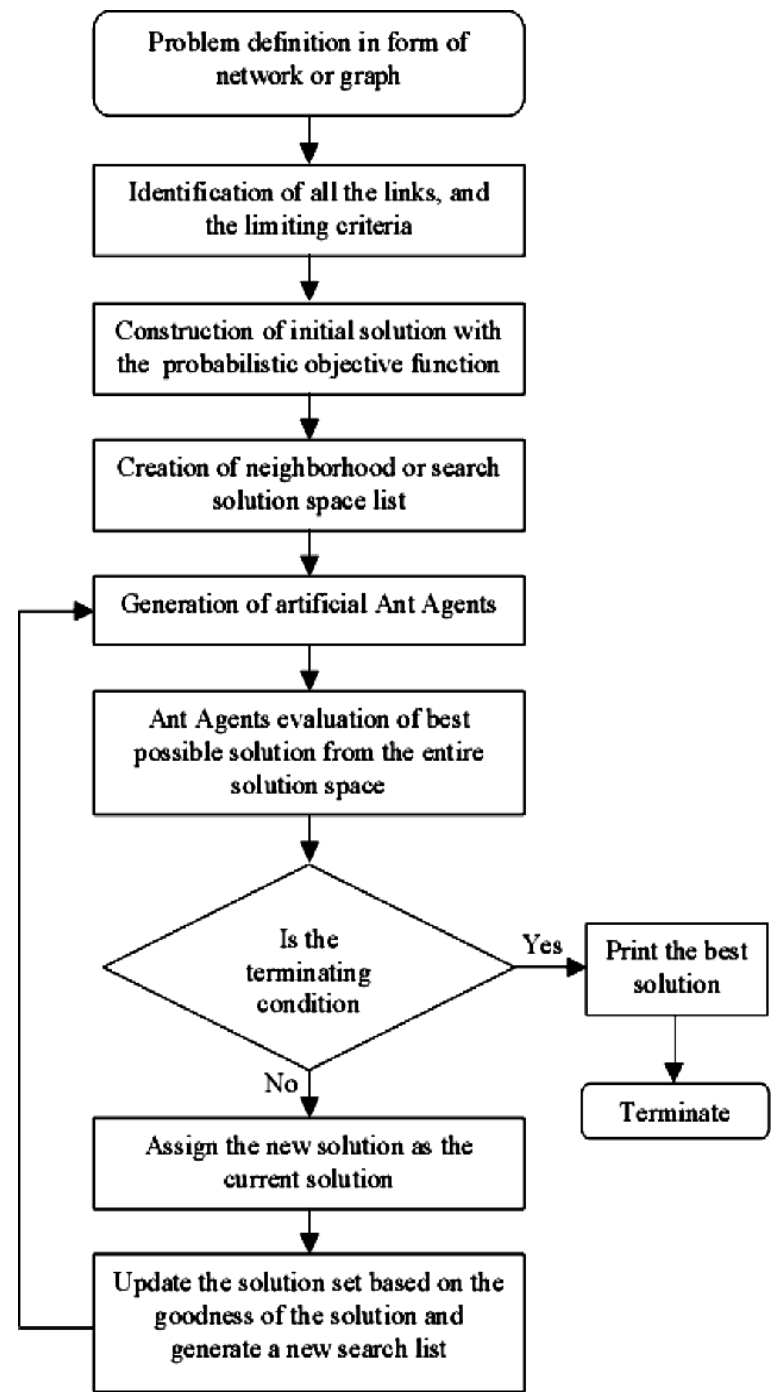

Figure 3. The ACO algorithm diagram

ACO was inspired by ants behaviour studies [1]. The ants algorithm is a new evolutionary optimization method first proposed by Dorigo et al. [2] to solve different combination optimization problems like the travelling salesman problem and the quadratic assignment problem. Dorigo and Dicaro [3] introduced the colony metaheuristic framwork. This enables ACO to be applied to other engineering problems. Abbaspour et al. [4] used ACO algorithms to estimate hydraulic parameters of unsaturated soil. Maier et al. [5] developed ACO algorithms to find near global optimum solution to a water distribution systems. However, not so much application of ACO was carried out for gas pipeline operation optimization, and therefore requires more applications in the oil and gas pipeline network design

\section{Application of ACO in Oil and Gas pipeline network systems}

To select a route for pipeline, need to consider on a good map, physical obstruction, ground condition, future development, number of building, traffic sensitively and safety assessment. Cost consideration for a project is the main criteria for companies to use different diameter and length and materials that those are depend on the physical obstructions and number of customers.

This type of algorithm (ACO) can also be used in some different stage of gas processing, LNG plants, cooling and heating stages, inside of refineries and for transmission and distribution pipeline networks between several stations, cities or refineries to consider the optimum required path (length) and to decrease the amount of usage of pipe lengths and hence determine flow rate and pressure drop at optimum length.

Usually the length of pipeline to transmit natural gas or oil between several stations or cities calculated from proportional of flow rate where, 


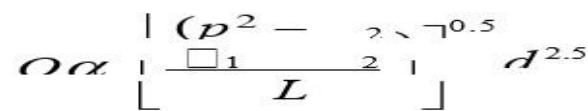

$Q \propto\left[\frac{\left(P_{1}^{2}-P_{2}^{2}\right)}{L}\right]^{0.5} d^{2.5}$

from general flow equation

That is generated

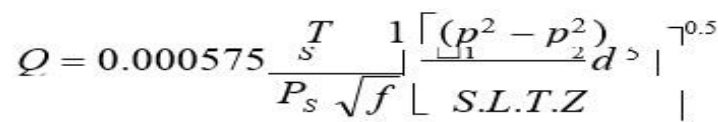

From equation 6 by any increasing or decreasing in the length of pipeline system between two states, the percentage of pressure drop and flow rate will be changed where are reverse to the length.

More shows in below picture, a simple calculation between state $\mathrm{v}_{0}$ and $\mathrm{v}_{1}$ with a physical obstruction to shows the effect of pheromone on the length to find minimum and optimum path.

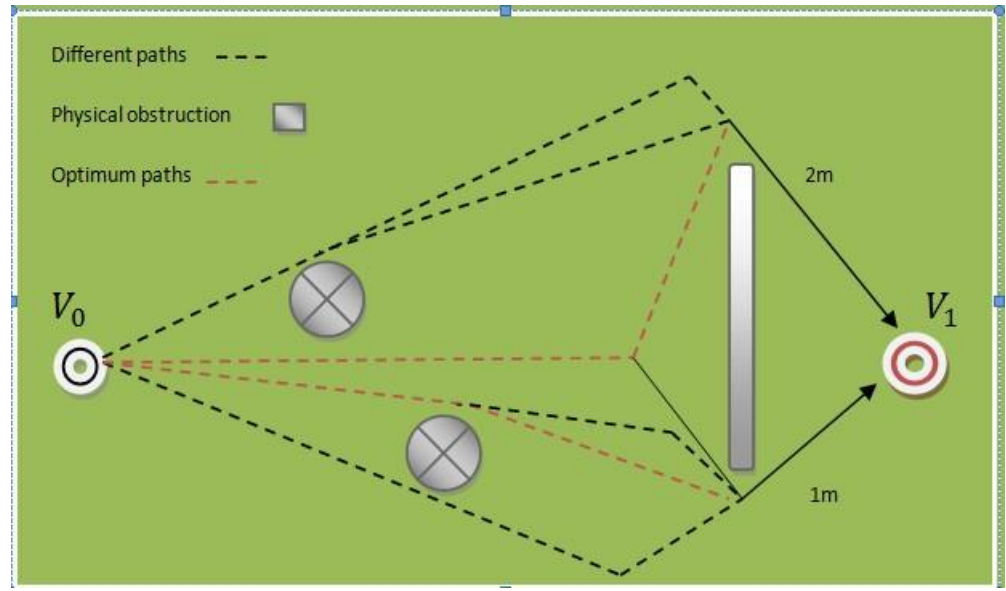

Figure 4. Minimum path between $\left(V_{0}, V_{1}\right)$

Assumes:

$\mathrm{Q}=10, \alpha=3$

$\alpha=\mathbf{3}$

$\beta=1, \mathrm{I} ?$

$\mathrm{A}_{0}=200$ distance for first ant

$\mathrm{A}_{1}=100$ distance for second ant

Amount of first pheromone for all ants

$\Delta \tau_{V V}\left(t_{0}\right)=0.3$

Then from equation (4)

Amount of pheromone for first ant is

$$
\begin{aligned}
& \tau_{V_{0} V_{1} 1}(t)=\tau_{V_{0} V_{1} 0}(t)+\left(\Delta \tau_{V_{0} V_{1} 1}^{A_{0}}(t) \times \rho\right) \\
= & 0.3+(0.05 \times 0.5)=0.325
\end{aligned}
$$

And for lower path is

$$
\begin{aligned}
& \tau_{V_{0} V_{1}}\left(t_{1}\right)=\tau_{V_{0} V_{1}}\left(t_{0}\right)+\left(\Delta \tau_{V V_{1}}^{A_{1}}\left(t_{1}\right) \times \rho\right) \\
& =0.3+(0.1 \times 0.5)=0.35
\end{aligned}
$$

Thus to calculate the amount of pheromone deposit in two paths need to use equation (3) and for upper path is 


$$
\tau_{V V_{0} 1}\left(t_{1}\right)=\tau_{V V_{01}}\left(t_{1}\right) *(1-\rho)=0.325 \times(1-0.5)=0.1625
$$

And for lower path is

$$
\tau_{V V}\left(t_{1}\right)=\tau_{V V}\left(t_{1}\right) *(1-\rho)=0.350 \times(1-0.5)=0.175
$$

(3)

More need to calculate the probability of chosen next edge and for upper path is

$$
\eta(V, V)={ }_{1}^{1}=0.5
$$

And for lower path is

$$
\eta(V, V)_{1}={ }_{-}^{1}=1
$$

Finally need to calculate the probability of two paths by equation (1) to define the optimum path

$$
\begin{aligned}
& { }_{U p}^{n} \frac{\omega_{0} \tau\left(V_{10}, V\right)^{\alpha} \times \eta(V, V)^{\beta}}{\sum_{A 0} \tau\left(V_{0}, V\right)^{\alpha} \times \eta(V, b)^{\beta}} \\
& =\frac{(0.1625)^{3} \times(0.5)^{1}}{\left[(0.1625)^{3} \times(0.5)^{1}\right]+\left[(0.175)^{3} \times(1)^{1}\right]}=\frac{0.002145}{0.007505}=P(0.285) \\
& \begin{array}{ll}
n_{\text {Down }} & \sqcup_{U} \tau(V, V)_{1}^{\alpha} \times \eta(V, V)^{\beta} \\
\sum_{A 1} \tau\left(V_{0}, V\right)^{\alpha} \times \eta(V, V)_{1}^{\beta}
\end{array} \\
& =\frac{(0.175)^{3} \times(1)^{1}}{\left\lceil(0.1625)^{3} \times(0.5)^{1}\right\rceil+\left\lceil(0.175)^{3} \times(1)^{1}\right\rceil}=\frac{0.00536}{0.007505}=P(0.715)
\end{aligned}
$$

The sum of two probabilities must be equal to one. The optimum or minimum path is chose from the higher probability which is showed the optimum length about $100 \mathrm{~cm}$ with an optimum pressure about 2440 psi and flow rate about $83^{*} 10^{\wedge} 6 \mathrm{~m}^{\wedge} 3 / \mathrm{hrError}$ D Digit expected. $\mathrm{m}^{3} / \mathrm{hr}$ which calculated from equation 7 .

Pup + PDown $=0.285+0.715=1$

\section{Visions}

Two fundamental visions need to be considered in gas and oil pipeline network systems where (i) the ants search for minimum path without initiate length and any limitations, it means the ACO will indicated the value of length with optimum length and (ii) the amount of length and limitations required as input data including the satisfying design route parameters. This enables the ACO model to provide the optimum required path. To exemplify, figure 4 depicts the transport salesman problem searching for minimum path from a source (A) in the Salford University to a particular store (destination B) in the center of the Manchester, similar to the Google Map that shows path between two states. As can be seen in figure 5, the longest route for the TSP is from ' $A$ ' to ' $B$ ' through black points where as ' $\mathrm{A}$ ' to ' $\mathrm{B}$ ' is the shortest distance through red points to required destination. Note, that the dotted lines signify the limitations or physical obstructions within various paths. This example is the analogy of the ACO model in defining the optimum length pipes in the network systems.

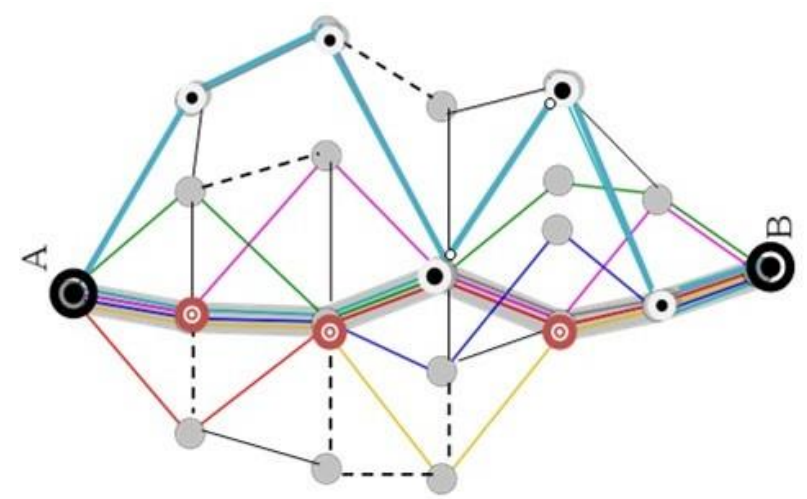

Figure 5. Transport Salesman Problem (TSP) 


\section{Computational Analysis}

The MATLAB version 12 is used base on Ant Colony Optimisation (ACO) algorithm codes to validate a problem which is chose as a significant problem of an example in petroleum and gas industry. This problem is chose to find the minimum / optimum lengths and optimum pressure and flow rates between 14 stations. Gas pipelines have to distribute between 14 cities (stations) while the pipeline network systems have to be in minimum/optimum length of pipelines, optimum average pressure and flow rates.

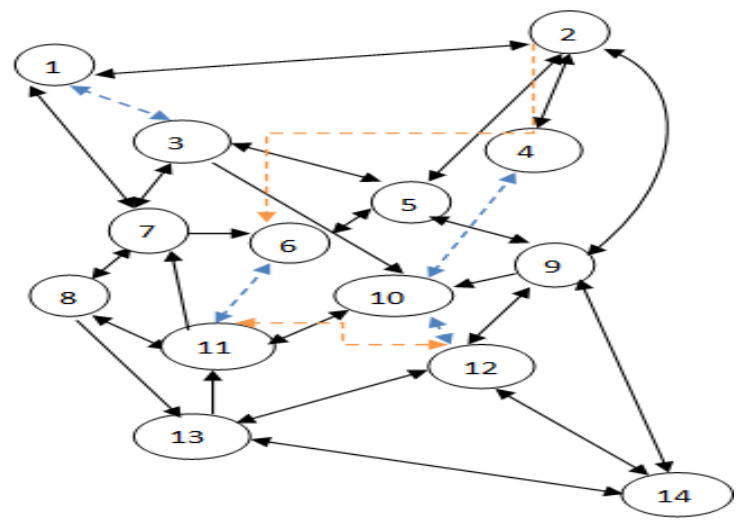

Figure 6. Pipeline network system graph between 14 stations

The example is run base on the ACO codes pass through the MATLAB analyser software. Figure 6 shows the distances between 14 stations. This initiate graph is designed by author to show directions and distances between 14 stations. This graph is just an initiate vision and will be edited by ACO algorithm after MATLAB running. The optimum dimension lengths and correct places of 14 stations will indicate by MATLAB plot results. Also ANTCOL software is used to compare with MATLAB results.

The length distances $(\mathrm{km})$ between 14 stations are chose based on the random variables results as Stochastic Variables (SV) of length which may shows as "SVMatrix = randi ([10 94], 14)" based on MATLAB analyser while this random numbers also are chose between 0.1 and $1.5 \mathrm{~km}$ for ANTCOL software. We are suggested varies limitations to validate the results of this problem. Different types of limitations were chosen between stations. Those limitations were chosen are;

- One way arrows black colour lines indicate one common way between each station.
- Two way arrows black colour lines indicate two common ways between each station

- Dotted blue colour lines show the large diameter pipelines distributions with length distance between 40 $<\mathrm{x}<60 \mathrm{~km}$

- Dotted orange colour lines show the upper-ground pipelines distributions with length distance $<40 \mathrm{~km}$

The MATLAB programme is run under below parameters:

Max-Iteration $=100$, number of Ants $=50$, alpha $=2$, beta $=1 ; \operatorname{tau} 0=1$, rho $=0.05, Q=1$, ethos $=1$. /D

In compare to MATLAB entry variables, below variables are chose for ANTCOL software.

Station extend ratio $=1$, Station numbers $=14$ Maximum Iteration $=2000$, Alpha $(\alpha)=1.783$,

$\operatorname{Beta}(\boldsymbol{\beta})=0.728$, Pheromone evaporation $=0.096$, $\square$ $=0.1, \mathrm{Q}=0.5$

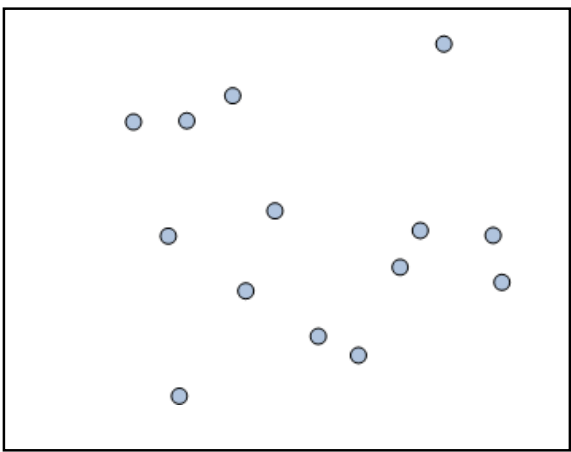

Figure 7. Random distances and replacement of 14 cities 
Figure 7 shows the random distances and replacement of 14 stations which are chose randomly for MATLAB analyser and ANTCOL software. The placements of 14 stations also are chose randomly under MATLAB codes in ANTCOL software. The 14 stations are chose in range of 10 and $96 \mathrm{~km}$ for MATLAB analyser and 0.1 and $1.5 \mathrm{~km}$ for ANTCOL. The figures below show the placement diagram of 14 stations of ANTCOL software versos each station point. The table ... shows the random data of 14 stations by MATLAB analyser.

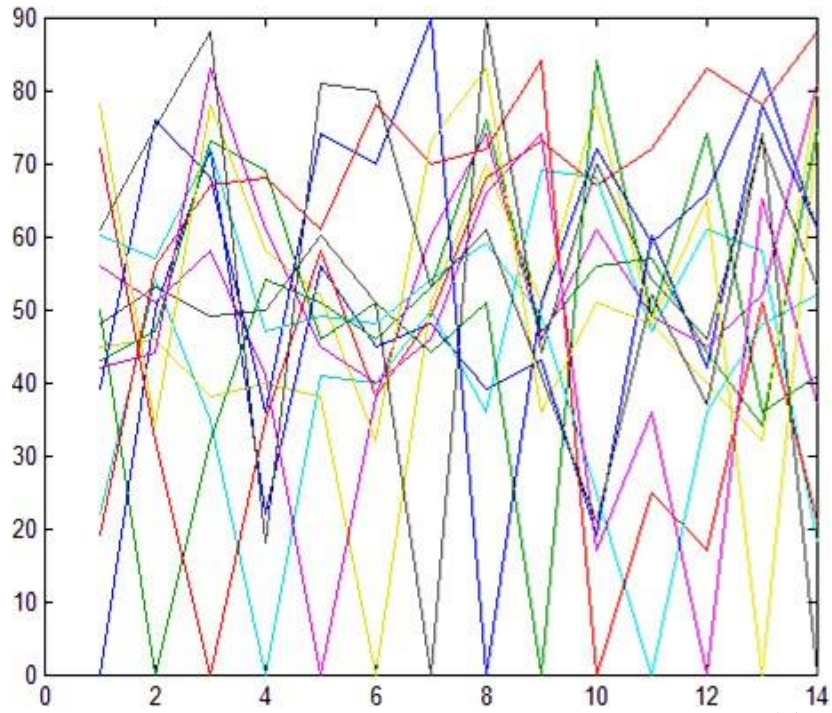

Figure 8. Random distances and replacement of 14 cities from MATLAB analyser

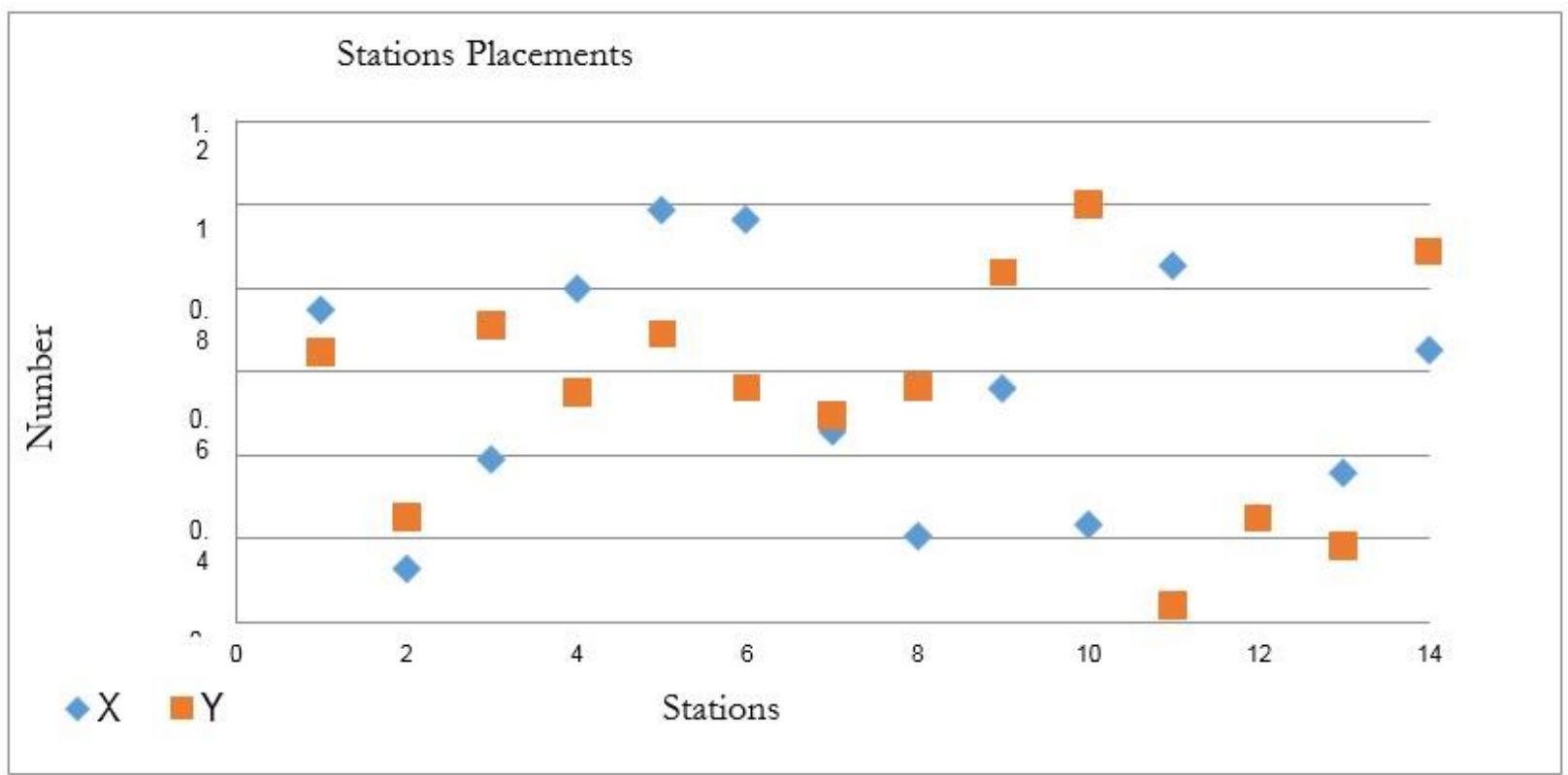

Figure 9. Random distances and replacement of 14 cities from ANTCOL software

The diagram below shows pseudo-code of Ant Colony Optimisation (ACO) algorithm while the ACO code is run under this pseudo-code by MATLAB

v.12. 


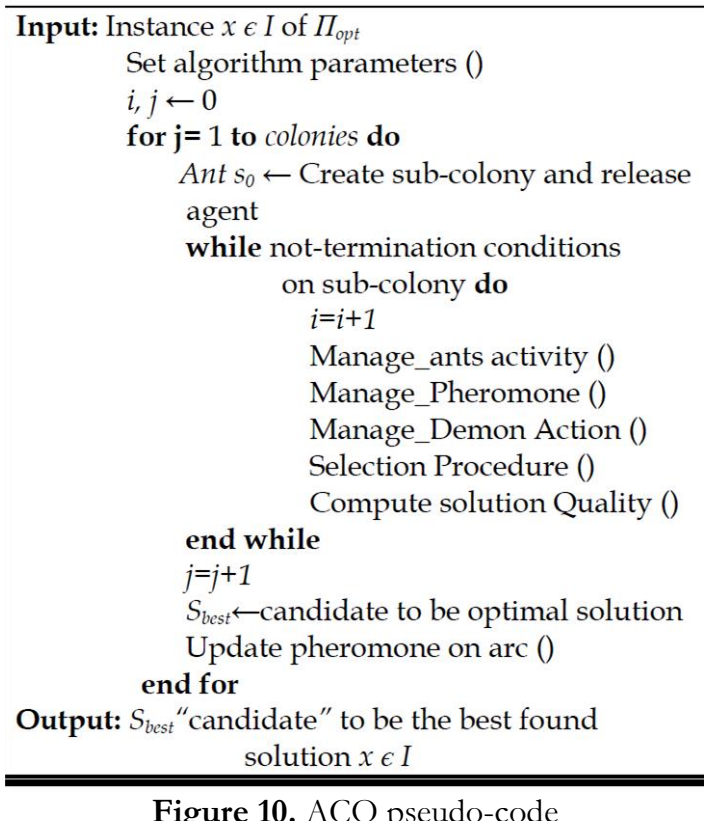

\section{Computational Results}

\section{MATLAB Analyser Results}

The MATLAB analyser is run to find minimum path and best link-path between 14 stations which are chose randomly. The ACO algorithm is used as an optimisation method. The figures below show the optimal results of 14 stations. The table 1 shows the stations and theirs targets. The station 6 is introduced as starting ant path while the last is 14. Column St. Ordered shows the linked-path between 14 stations.

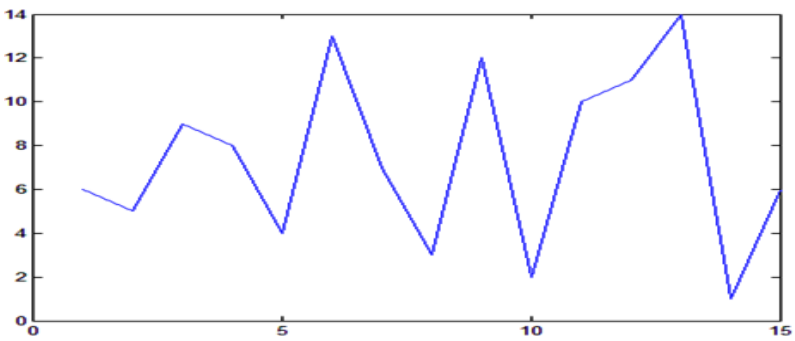

Figure 11. Best linked-path between 14 stations from MATLAB analyser results

Table 1

Best linked-path between 14 stations from MATLAB analyser results

\begin{tabular}{lccc}
\hline ID & Station & Target & St. Ordered \\
\hline 1 & St.1 & St.6 & 6 \\
2 & St.2 & St.10 & 5 \\
3 & St. 3 & St.12 & 9 \\
4 & St.4 & St.13 & 8 \\
5 & St.5 & St.9 & 4 \\
6 & St.6 & St.5 & 13 \\
7 & St.7 & St.3 & 7 \\
8 & St.8 & St.4 & 3 \\
9 & St.9 & St.8 & 12 \\
10 & St.10 & St.11 & 2 \\
11 & St.11 & St.14 & 10 \\
12 & St.12 & St.2 & 11 \\
13 & St.13 & St.7 & 14 \\
14 & St.14 & St.1 & 1 \\
\hline
\end{tabular}


The figure 11 shows the linked-path diagram between 14 stations. As we can see the cycle starts from point 6 to point 1 . This cycle is the optimum linked-path which is introduced by MATLAB analyser. This cycle may be a part of distribution and transmission pipeline network systems in petroleum and gas industry.

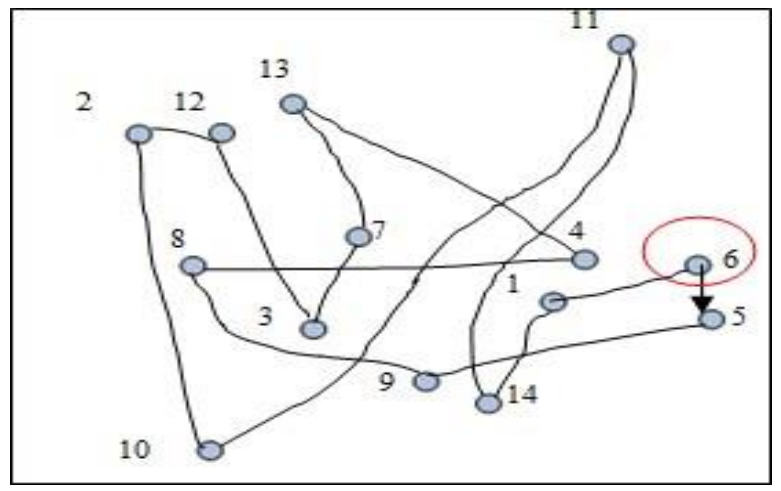

Figure 11. Best linked-path between 14 stations by MATLAB analyser

One of the most significant parameters to minimise the final cost of pipleine network systems is minimum required pipeline length. In this case study the minimum required length is calculated about $526 \mathrm{~km}$ from and to station 6 pass through the stations 5, 9, 8,
$4,13,7,3,12,2,10,11,14,1$ after 100 iterations. The figure 12 shows the range of pipeline length from 600 $\mathrm{km}$ in iteration 3 to $526 \mathrm{~km}$ in iteration 100 . As we can see by incaresing the rate of iteration, the best length (cost) decrease from 600 to $526 \mathrm{~km}$.

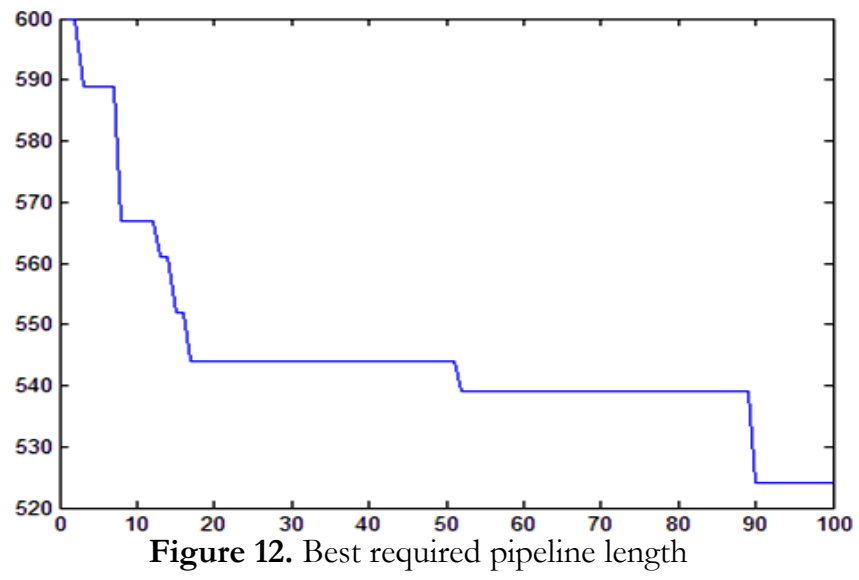

Figure 13. shows the ants travelling to seek minimum length. The overall travelling by 50 ants is concluded less than $850 \mathrm{~km}$. Figure 14 shows the decreasing and

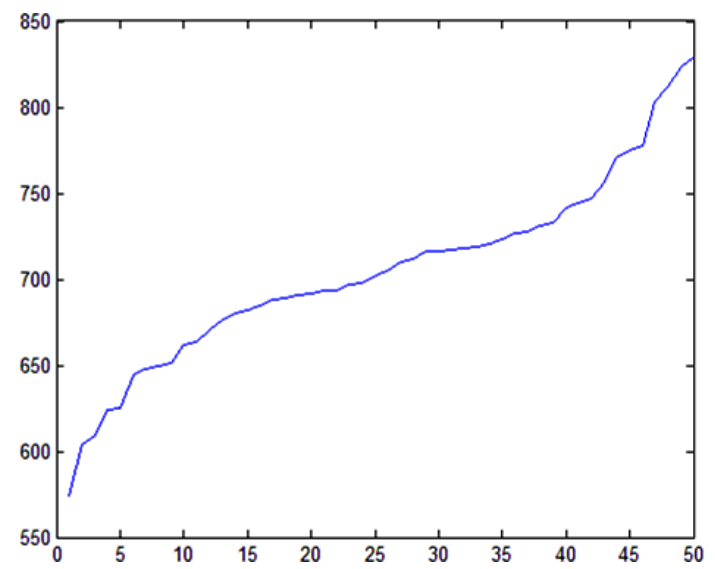

increasing of ants number during ants travelling which is a ants $*$ ants matrix.

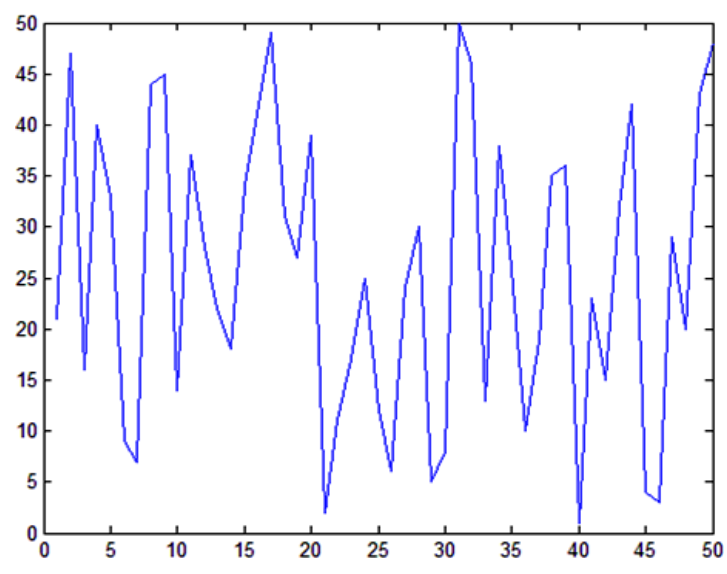


Figure 13. Ant travelling length

The MATLAB results show the best linked-path form / to station 6 with minimum optimum required length about $526 \mathrm{~km}$ between 14 stations. Usually the length of pipeline to transmit natural gas or oil between
Figure 14. Ants number amount during ants travelling several stations or cities calculated from proportional of flow rate.

Where,

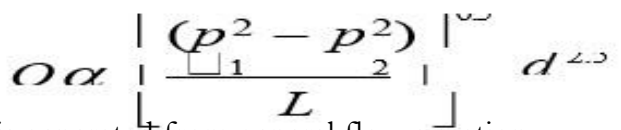

$$
\begin{aligned}
& \sim \frac{\Delta \mathrm{P}_{1}^{2}-\mathrm{P}_{2}^{2}}{\mathrm{~L}}= \\
& \mathrm{d} \text { That is generated from general flow equation } \\
& Q=0.000575 \frac{\frac{S}{S}}{P_{S} \sqrt{f}}\left|\frac{1 \mid\left(p^{2}-p^{2}\right)}{\text { S.L.T.Z }}\right|^{0.5}
\end{aligned}
$$

percentage of pressure drop and flow rate will be changed where are reverse to the length.

length of pipeline system between two states, the So,

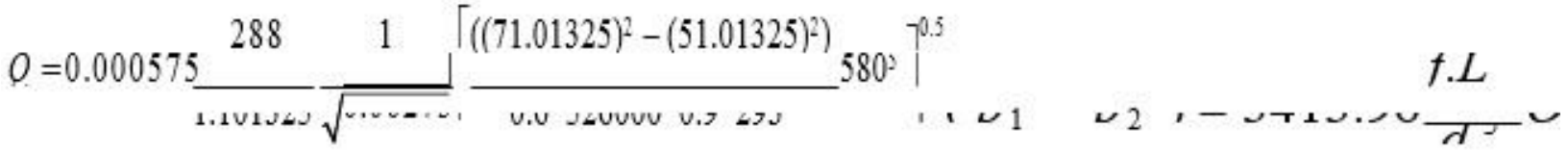

$$
\begin{aligned}
& \left(p_{1}^{2}-p_{2}^{2}\right)=3413.96^{0.00275^{* 526000}} 97441.1968^{2}
\end{aligned}
$$

The optimum pressure drop and flow rate are calculated from equations 6 and 7 at optimum length (about $526000 \mathrm{~m}$ ), approximately 714.638 bar (gauge) and $97441.1968 \mathrm{~mm}^{3} / \mathrm{hrr}$ respectively.

As part of this paper ANTCOL software is used to use for comparison results to MATLAB results. The following shows the ANTCOL software results.

ANTCOL Analyser Results

The graph below shows the ants pathways through the 14 stations. It is indicating, station 11 is chose as first ant path-way. The assigned number of stations, first ant path-way, the direction of ants and movements between stations are chose randomly which section "probability of choice" in table 1 indicates those. Table 1 shows the probability of choice, pheromone distributions and station targets. The results show the station 11 as best place for starting point (green colour point) and the optimum travel length between 14 stations approximately 3.631 kilometres.

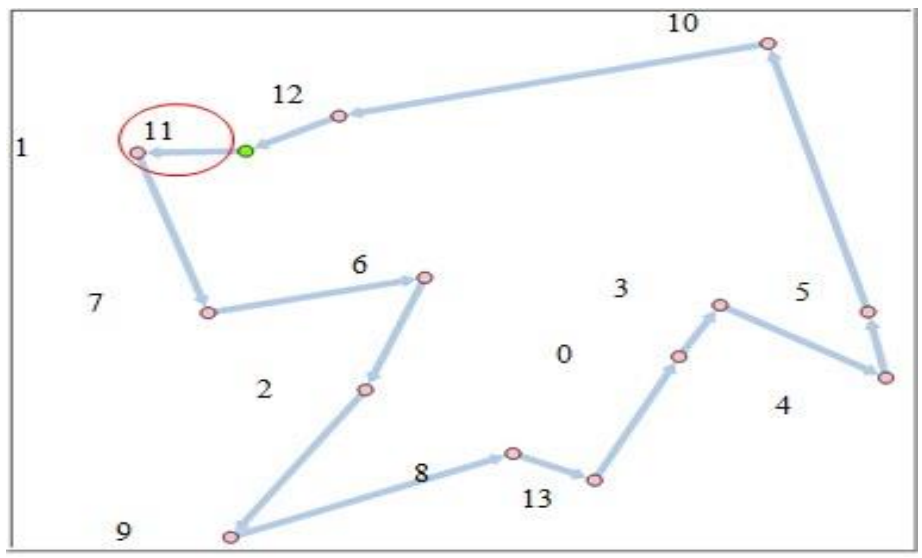

Figure 15. Stations choice probability 


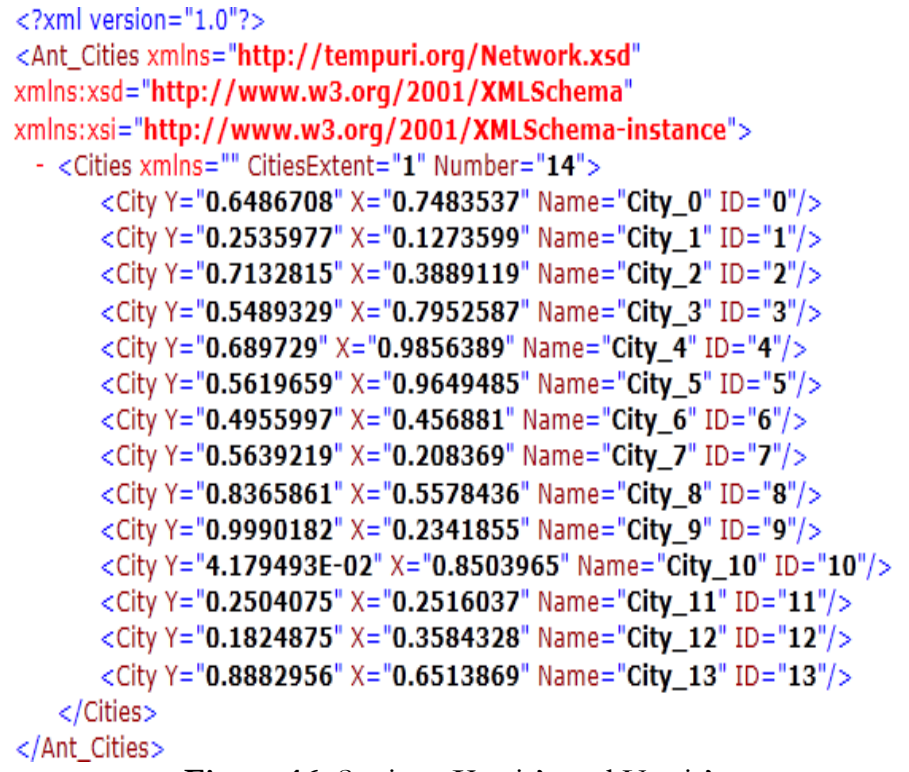

Figure 16. Stations X axis's and Y axis's

Figure 16 shows the stations calculations based on ANTCOL optimisation algorithm. The placement of all stations in $\mathrm{X}$ and $\mathrm{Y}$ are showed from 4.2 and $0.12 \mathrm{~km}$. Station 11 is chose randomly in 0.250 in $\mathrm{X}$-axis and 0.251 in $\mathrm{Y}$-axis.

The optimum length of ant path travelling is found approximately $3.631 \mathrm{~km}$ which is significant final targets of Ant Colony Optimisation (ACO) Algorithm application's in petroleum and gas industrial fields. Transmission and distribution pipeline networks between several stations, cities or refineries are important sections in oil and gas fields which are need optimum required path (length) to decrease the amount of usage of pipe lengths and hence determine optimum flow rate and pressure drop at optimum length.

$$
\left(p^{2}-p_{2}^{2}\right)=3413.96 \frac{0.00275^{* 3631}}{580^{5}} 1515480^{2}
$$

The optimum pressure drop and flow rate are calculated from equations 6 and 7 at optimum length (about $3631 \mathrm{~m}$ ), approximately 1192.83 bar (gauge) and $1515480 * 10^{6} \mathrm{~mm}^{3} / \mathrm{hrr}$ respectively. Appendix A shows the movements graphs of each ant from each station to find minimum path between them with their significant parameters.

\section{MATL $A B$ and ANTCOL software comparisons}

The results of both MATLAB and ANTCOL analysers show the differences in behind algorithms methods. The comparisons results show in figures 18 and 19. Figure 18 shows the linked-path between 14 stations based on MATLAB and ANTCOL analysers. The best linked-path starting point is station 6 for MATLAB analyser while it is station 11 for ANTCOL. As we know the proportion of flow-rate and length are reverse. It shows by increasing the length, flow rate amount changes to $0.098106 \mathrm{~mm}^{3} / \mathrm{hrr}$ in compare to ANTCOL results. The results show the MATLAB analyser results are more realistically due to high performance of MATLAB analyser to optimise data based on ACO algorithm as a heuristic solution method.

\begin{tabular}{|l|l|l|l|l|}
\hline ID & $\begin{array}{l}\text { Best } \\
\text { Starting } \\
\text { point }\end{array}$ & $\begin{array}{l}\text { Optimum } \\
\text { Flow- } \\
\text { Rate }\end{array}$ & $\begin{array}{l}\text { Optimum } \\
\text { Length }\end{array}$ & $\begin{array}{l}\text { Pressure } \\
\text { Drop }\end{array}$ \\
\hline ANTCOL & 11 & 1.5 & 3.63 & 1192.83 \\
\hline MATLAB & 6 & 0.098 & 526 & 714.638 \\
\hline
\end{tabular}


Ant data: Name $=$ BestForIter, Idx $=0$, Start City Idx $=11$, Curr. City Idx $=11$

Curr. Epoch $=2001$, Travel length $=3.63$.

ant Colony System: CitiesNum=14, Symm Mutable=true, , Symm=true, AntID=0, StartCity=11,

StartPher $=0.0714286$, Alpha $=1.783$, Beta $=0.728$, EvapFactor $=0.096$, CitiesExtent $=1$

Ant Colony System: AcsLocEvapPactor $=0.1$, AcsRndSe1Trsh $=0.5$,

AcsPherSource $=$ Ant Best In Iteration

Mutation not enabled

Reset not enabled

\begin{tabular}{|l|}
\hline Ant Path From City_11 \\
\hline
\end{tabular}

\begin{tabular}{|r|r|r|r|r|r|}
\hline \multicolumn{1}{|c|}{ ID } & Target & Distance & Pheromone & Prob. of choice & Updated Pher. \\
\hline 1 & City_l & 0.12428 & 0.33245 & 0.42128 & 0.57575 \\
\hline 7 & City_7 & 0.32072 & 0.43389 & 0.36809 & 0.67764 \\
\hline 6 & City_6 & 0.25773 & 0.30408 & 0.29286 & 0.54726 \\
\hline 2 & City_2 & 0.22805 & 0.37946 & 0.48149 & 0.62297 \\
\hline 9 & City_9 & 0.32494 & 0.37868 & 0.33421 & 0.56355 \\
\hline 8 & City_8 & 0.36213 & 0.41447 & 0.47672 & 0.65813 \\
\hline 13 & City_13 & 0.10688 & 0.39576 & 0.58473 & 0.57744 \\
\hline 0 & City_0 & 0.2585 & 0.49523 & 0.43314 & 0.65837 \\
\hline 3 & City_3 & 0.11022 & 0.42861 & 0.56603 & 0.60417 \\
\hline 4 & City_4 & 0.23679 & 0.3726 & 0.30374 & 0.61607 \\
\hline 5 & City_5 & 0.12943 & 0.35154 & 0.48746 & 0.59492 \\
\hline 10 & City_10 & 0.53263 & 0.45684 & 0.31309 & 0.70069 \\
\hline 12 & City_12 & 0.51169 & 0.40881 & 0.38983 & 0.65245 \\
\hline 11 & City_11 & 0.12659 & 0.36027 & 0.59813 & 0.60369 \\
\hline & & & & & \\
\hline
\end{tabular}

\begin{tabular}{|r|r|r|r|r|r|}
\hline \multicolumn{1}{|c|}{ ID } & Target & \multicolumn{1}{c|}{ Distance } & Pheromone & Prob. of choice & Opdated Pher. \\
\hline 1 & City_1 & 0.73601 & 0.071429 & 0.0058208 & 0.071429 \\
\hline 2 & City_2 & 0.3652 & 0.071429 & 0.0096951 & 0.071429 \\
\hline 3 & City_3 & 0.11022 & 0.42861 & 0.56603 & 0.60417 \\
\hline 4 & City_4 & 0.24081 & 0.071429 & 0.013129 & 0.071429 \\
\hline 5 & City_5 & 0.2333 & 0.071429 & 0.013435 & 0.071429 \\
\hline 6 & City_6 & 0.32922 & 0.071429 & 0.010456 & 0.071429 \\
\hline 7 & City_7 & 0.54659 & 0.071429 & 0.0072287 & 0.071429 \\
\hline 8 & City_8 & 0.26759 & 0.071429 & 0.012158 & 0.071429 \\
\hline 9 & City_9 & 0.62218 & 0.071429 & 0.0065782 & 0.071429 \\
\hline 10 & City_10 & 0.6154 & 0.071429 & 0.0066309 & 0.071429 \\
\hline 11 & City_11 & 0.63669 & 0.071429 & 0.0064687 & 0.071429 \\
\hline 12 & City_12 & 0.60775 & 0.071429 & 0.0066915 & 0.071429 \\
\hline 13 & City_13 & 0.2585 & 0.45285 & 0.33568 & 0.65837 \\
\hline
\end{tabular}

Figure 17. Station's target results

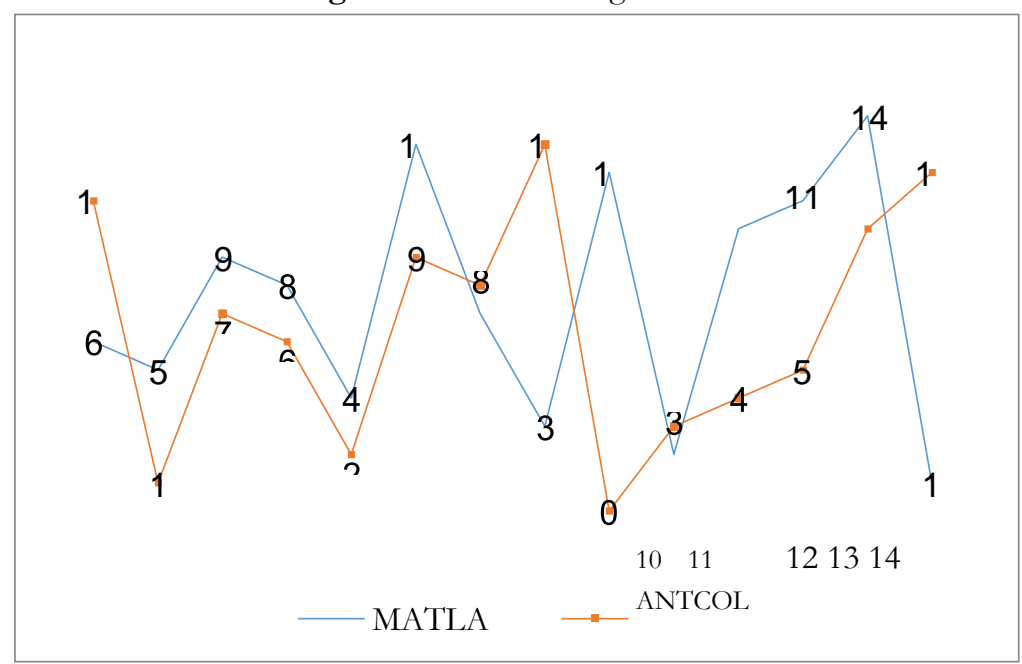

Figure 18. Comparisons results of linked-path 


\section{Conclusion}

Due to the increasing demands in oil and gas in recent decades, Ant Colony Optimization algorithm (ACO) can provide powerful tools for optimisation activities in defining the optimum path in pipeline network systems which is achieved the optimum pressure and flow rate from general flow equation. This will have significant effect on both initiate capital expenditure and longterm operating costs in gas and petroleum industries. The ACO algorithm may prepare robust optimum solution methods to find minimum / optimum length, pressure drop, velocity, flow rate and etc from real data in oil and gas fields and systems.

\section{References}

1. Deneubourg JL, Pasteels JM, Verhaeghe JC. Probabilistic behavior in ants: strategy of errors. $J$ Theoretical Boil. 1983; 105: 259-272.

2. Dorigo M, Maniezo V, Colomi A. The ant system: optimization by a colony cooperating ants. IEEE Trans Syst Man Cybernet. 1996; 229-242.

3. Dorigo M, Di Caro G. The ant colony optimization metaheuristic, In: Corne. Dorigo M, Glover F, editors, New idea in optimization. London: McGraw-Hi 1999; 11-32.

4. Abbaspour KC, Schulin R, Van Genuchten MT. Estimating unsaturated soil hydraulic parameters using ant colony optimization. Adv W ater Resour. 2001; 24(8): 827-933.

5. Maier HR, Simpson AR, Zecchin AC, Foong WK, Phang KY, Seah HY, Tan CL. Ant colony optimization for design of water distribution systems. $J W$ ater Resour Plan Manag. ASCE 2003; 129(3): 200-209.

6. LJS Website, http://js.academicdirect.org/A07/43_57.htm 7. 4shared Website, http://dc243.4shared.com/img/hMTdSx 8/preview.html

8. Omicsonline Website, http:/ / omicsonline.org/ArchiveJCSB/2009/June/03/J CSB2.186.php

9. Efe Website, http://efe.ege.edu.tr/ aydin/research.html 10. Wikipedia Website, http://en.wikipedia.org/wiki/Ant_colony_optimization 11. CodeProject Website, http:// codeproject.com/ant colony optimisation

\section{Appendix A}

Table 3

Distances between 14 stations by random results between 10 and $96 \mathrm{~km}$ from MATLAB analyser

\begin{tabular}{|c|c|c|c|c|c|c|c|c|c|c|c|c|c|c|}
\hline & 1 & 2 & 3 & 4 & 5 & 6 & 7 & 8 & 9 & 10 & 11 & 12 & 13 & 14 \\
\hline 1 & 0 & 50 & 72 & 22 & 56 & 45 & 48 & 39 & 43 & 19 & 60 & 42 & 78 & 61 \\
\hline 2 & 50 & 0 & 32 & 54 & 51 & 46 & 53 & 76 & 47 & 56 & 57 & 44 & 34 & 75 \\
\hline 3 & 72 & 32 & 0 & 35 & 58 & 38 & 49 & 68 & 73 & 67 & 72 & 83 & 78 & 88 \\
\hline 4 & 22 & 54 & 35 & 0 & 41 & 40 & 50 & 36 & 69 & 68 & 47 & 61 & 58 & 18 \\
\hline 5 & 56 & 51 & 58 & 41 & 0 & 38 & 60 & 74 & 46 & 61 & 49 & 45 & 52 & 81 \\
\hline 6 & 45 & 46 & 38 & 40 & 38 & 0 & 51 & 70 & 51 & 78 & 48 & 40 & 32 & 80 \\
\hline 7 & 48 & 53 & 49 & 50 & 60 & 51 & 0 & 90 & 44 & 70 & 54 & 46 & 73 & 53 \\
\hline 8 & 39 & 76 & 68 & 36 & 74 & 70 & 90 & 0 & 51 & 72 & 59 & 66 & 83 & 61 \\
\hline 9 & 43 & 47 & 73 & 69 & 46 & 51 & 44 & 51 & 0 & 84 & 49 & 74 & 36 & 41 \\
\hline 10 & 19 & 56 & 67 & 68 & 61 & 78 & 70 & 72 & 84 & 0 & 25 & 17 & 51 & 21 \\
\hline 11 & 60 & 57 & 72 & 47 & 49 & 48 & 54 & 59 & 49 & 25 & 0 & 36 & 48 & 52 \\
\hline 12 & 42 & 44 & 83 & 61 & 45 & 40 & 46 & 66 & 74 & 17 & 36 & 0 & 65 & 37 \\
\hline 13 & 78 & 34 & 78 & 58 & 52 & 32 & 73 & 83 & 36 & 51 & 48 & 65 & 0 & 74 \\
\hline 14 & 61 & 75 & 88 & 18 & 81 & 80 & 53 & 61 & 41 & 21 & 52 & 37 & 74 & 0 \\
\hline
\end{tabular}

All above numbers in table 3 are chose randomly based on SVMATRIX = ([10 96], 14) code by MATLAB analyser. The zeros 0 results are distance of each station to same station. Distance of station 6 to station 6 is zero. Some of the results may be introduced as:

- Distance of station 1 to station 2 is $50 \mathrm{~km}$ while station 2 to 1 is in same $\mathrm{km}$

- Distance of station 1 to station 9 is $43 \mathrm{~km}$ while station 9 to 1 is in same $\mathrm{km}$

- Distance of station 6 to station 2 is $46 \mathrm{~km}$ while station 2 to 6 is in same $\mathrm{km}$ 


\section{Appendix B}
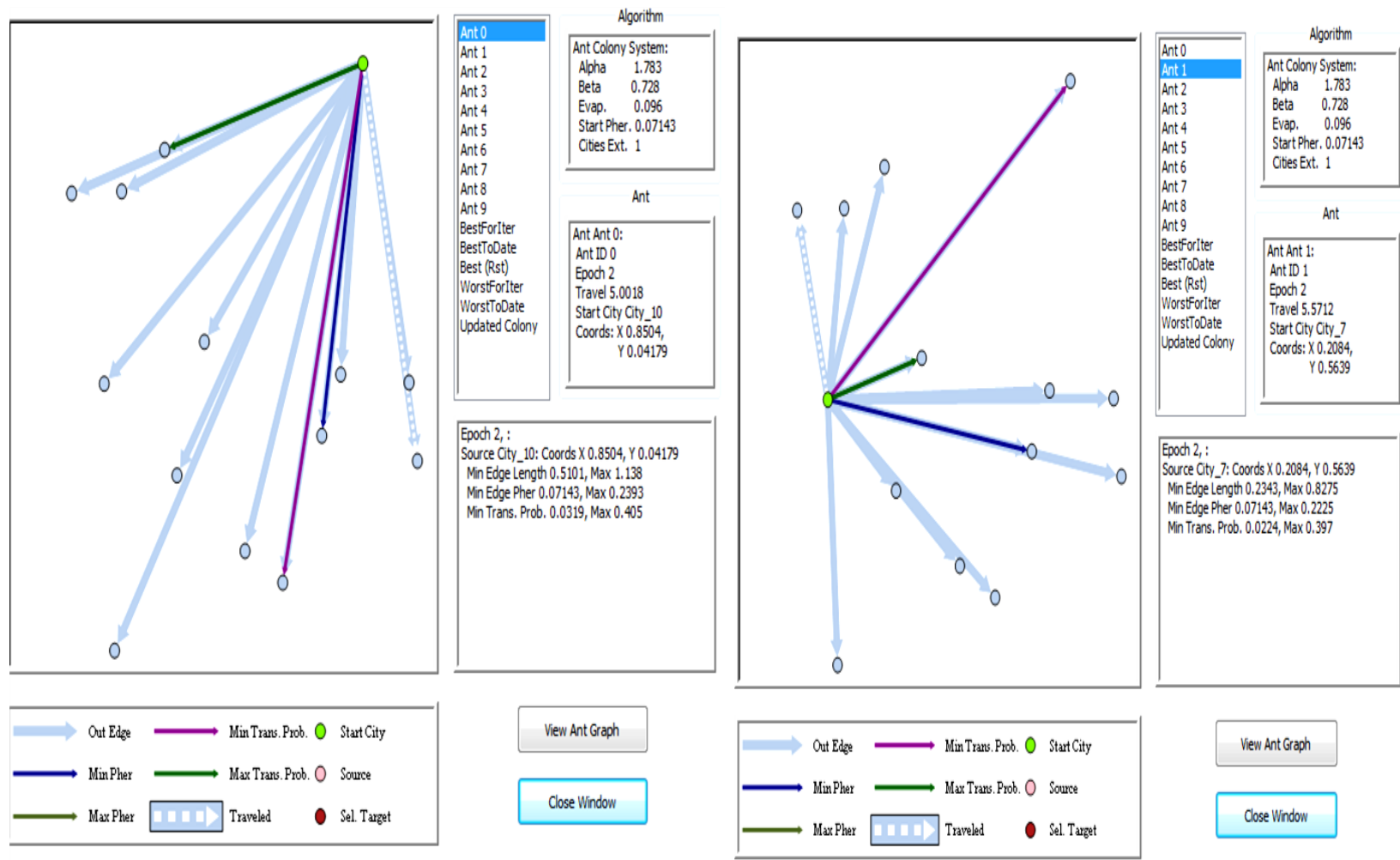

View Ant Graph

Close Window
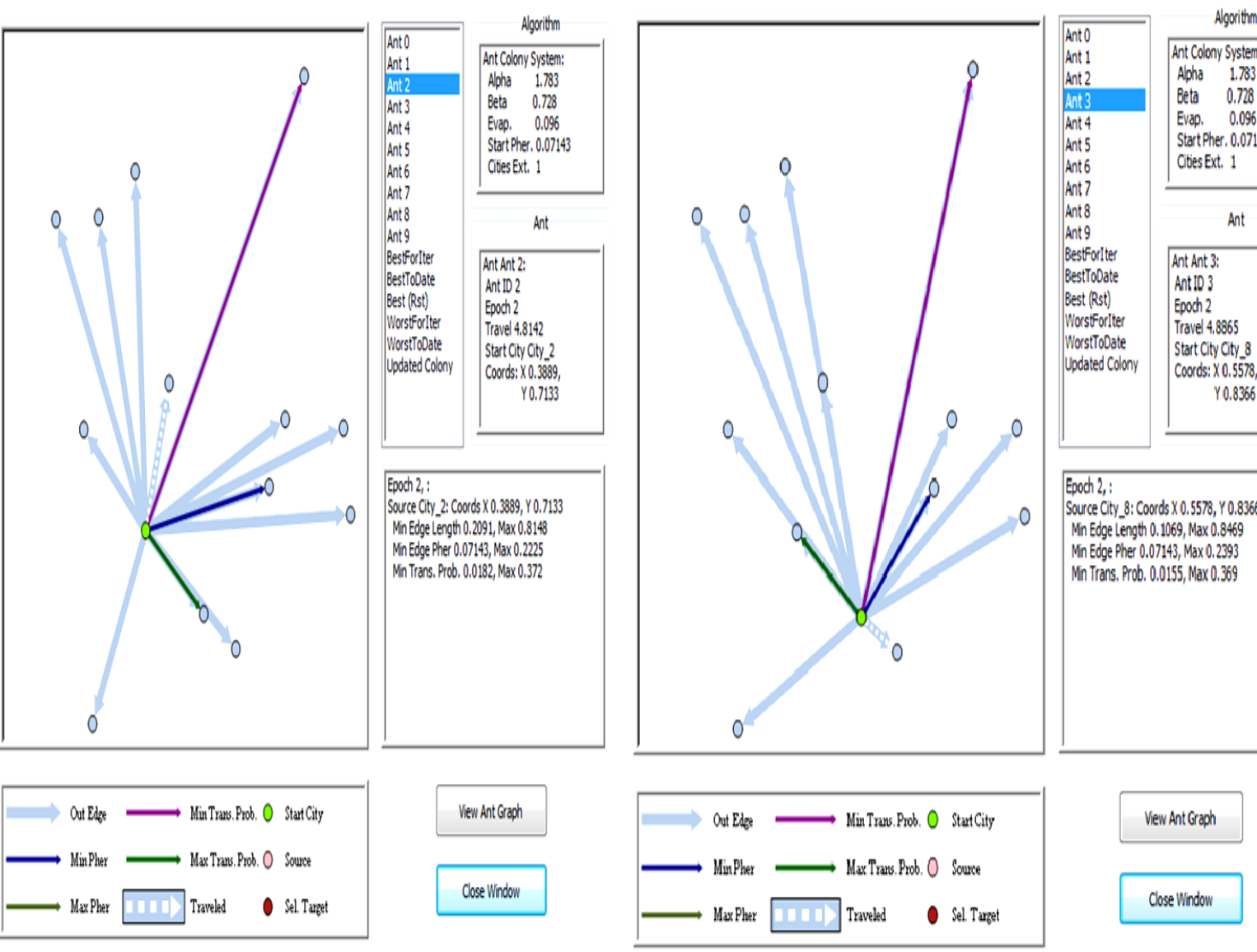

View Ant Groph

Close Window 

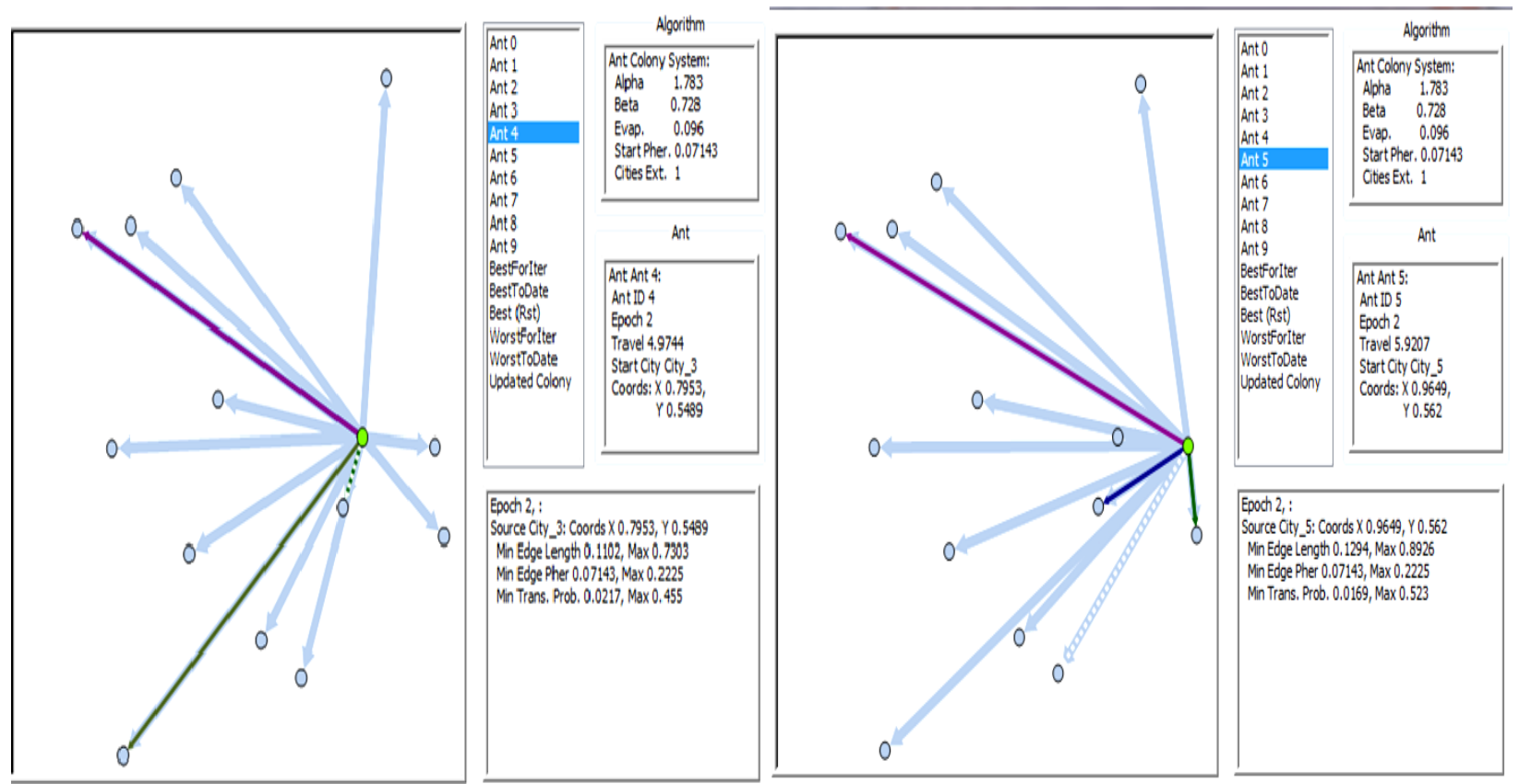

Epoch 2,:

Source City 5: Coords X0.9649, Y0.562

Min Edge Length 0.1294, Max 0.8926

Min Edge Pher 0.07143 , Max 0.2225

Min Trans. Prob, 0.0169, Max 0.523
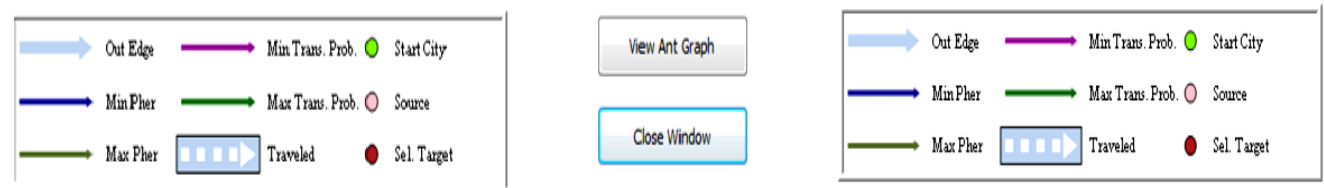

\section{View Ant Graph}

Close Window
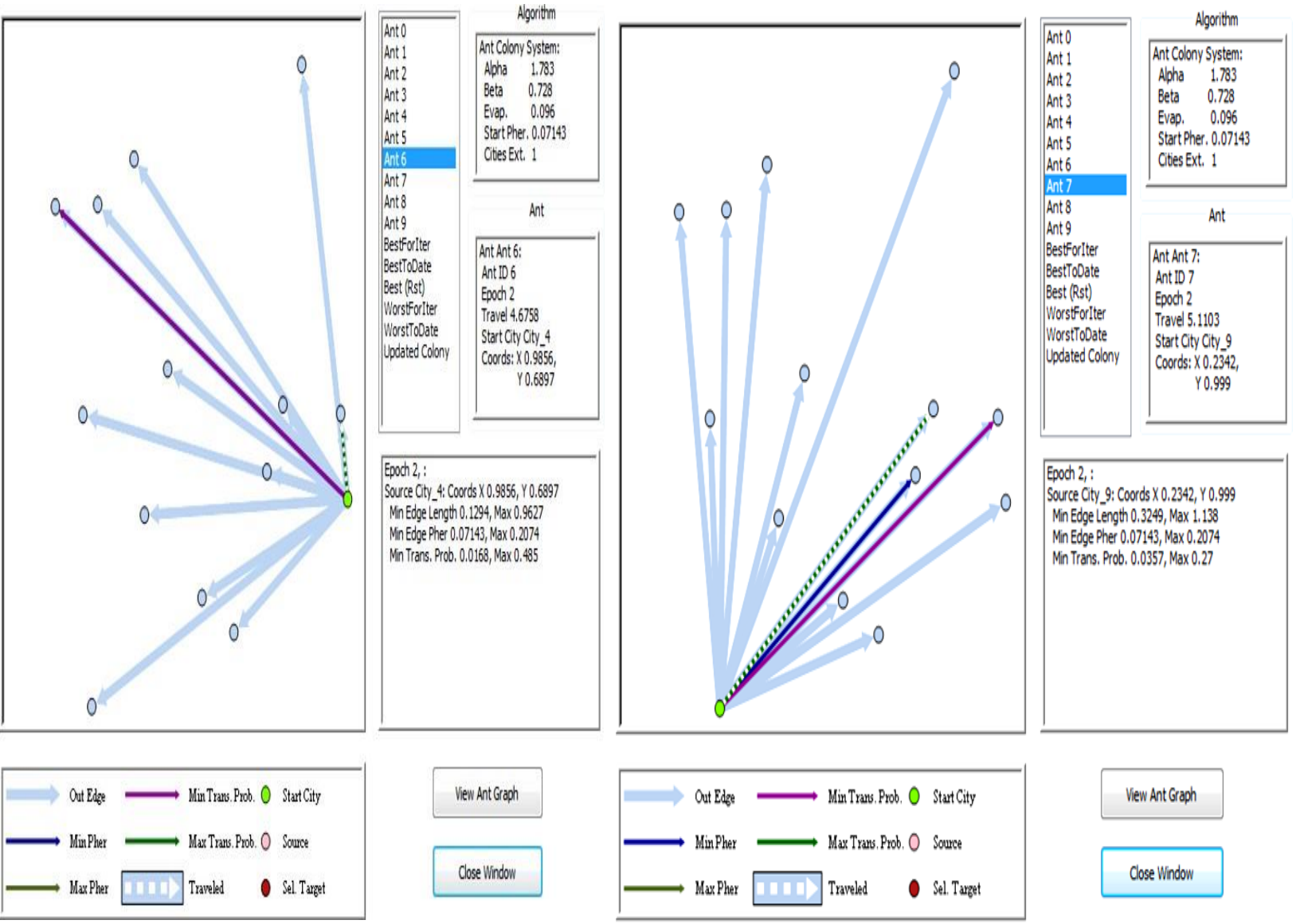

View Ant Graph

Close Window 

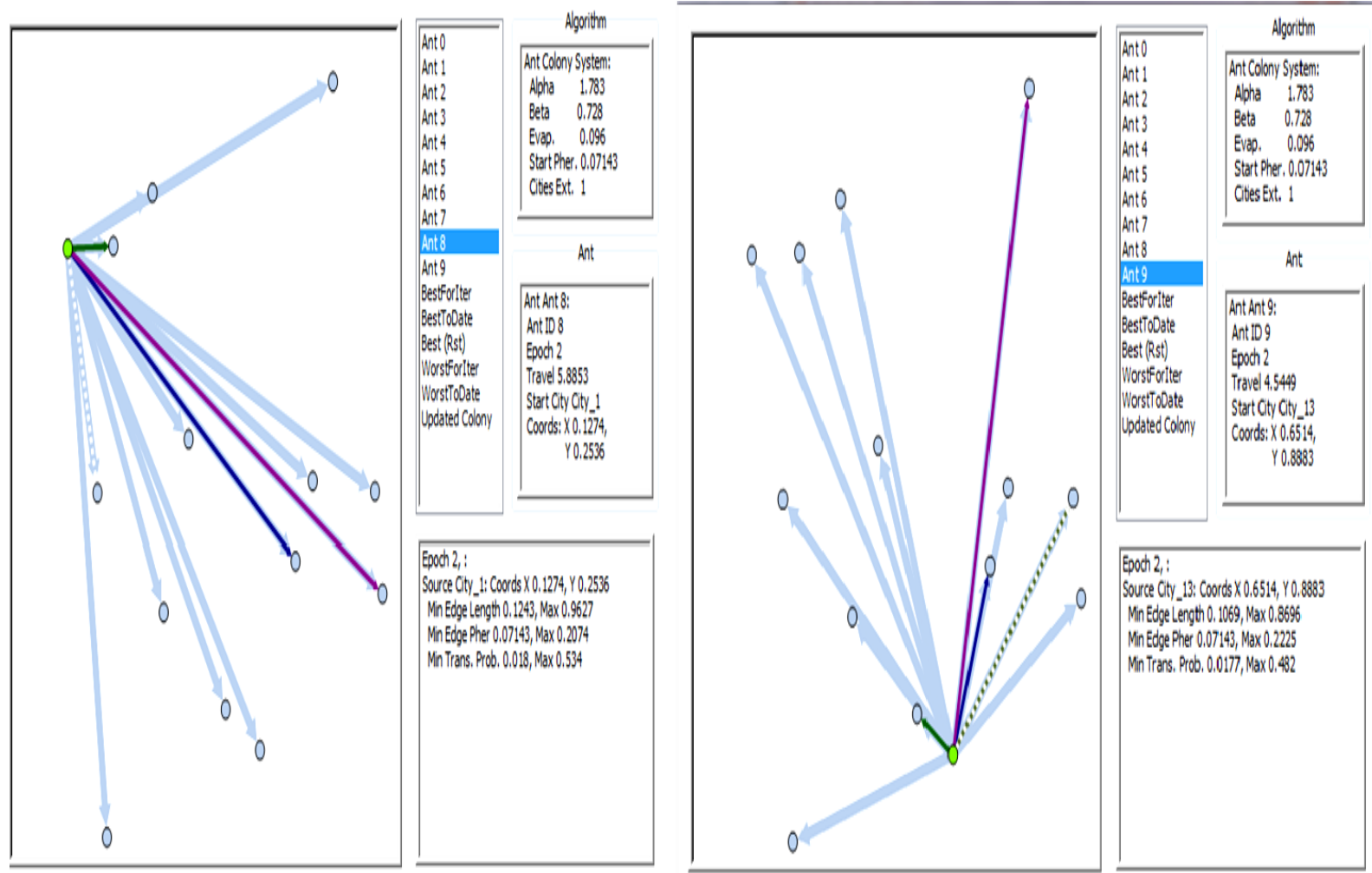

Ants

Ants

Bestforiter

Bestioloate

Best (Rst)

Worstoriter

Worstiooate

updated Colony

Ant

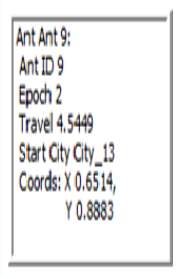

Epoct 2;:

Source City_13: Coords X0.65:44, Y0.8883

Min Edge Length 0. 1069, Max 0.8696

Min Edgege Pher 0.07143, Max 0.2225

Min Trans. Probo, 0.0177, Max 0.482
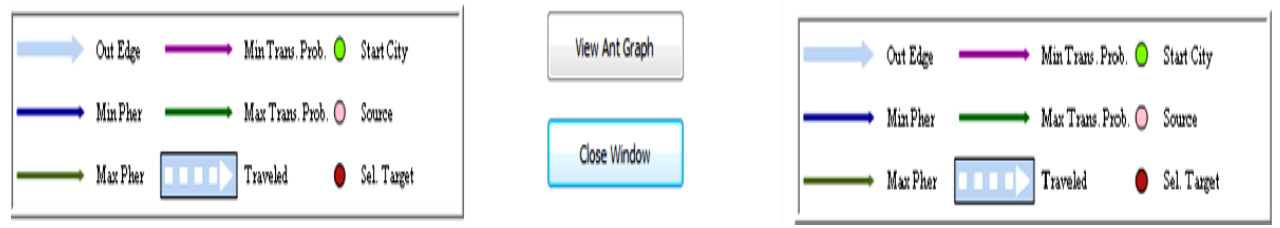

View Ant Graph

Close Window

\section{SJIS}

Copyright: (C) 2021 The Author(s); This is an open-access article distributed under the terms of the Creative Commons Attribution License (http://creativecommons.org/licenses/by/4.0), which permits unrestricted use, distribution, and reproduction in any medium, provided the original work is properly cited.

Citation: Nakhaei A, Soltani F. Modelling and Optimisation in the Design of Pipeline Network Systems Using Ant Colony Optimisation Algorithm (ACO). SJIS, 2021; 3(4): 1-17.

https://doi.org/10.47176/sjis.3.4.1 